Article

\title{
A Retrospective Comparative Study of Sodium Fluoride (NaF-18)-PET/CT and Fluorocholine (F-18-CH) PET/CT in the Evaluation of Skeletal Metastases in Metastatic Prostate Cancer Using a Volumetric 3-D Radiomics Analysis
}

\author{
Kalevi Kairemo ${ }^{1,2, *}$, S. Cheenu Kappadath ${ }^{3}$, Timo Joensuu ${ }^{4}\left(\mathbb{D}\right.$ and Homer A. Macapinlac ${ }^{2}$ \\ 1 Department of Theragnostics, Docrates Cancer Center, 00180 Helsinki, Finland \\ 2 Department of Nuclear Medicine, MD Anderson Cancer Center, Houston, TX 77030, USA; \\ hmacapinlac@mdanderson.org \\ 3 Department of Imaging Physics, MD Anderson Cancer Center, Houston, TX 77030, USA; \\ skappadath@mdanderson.org \\ 4 Department of Medical Oncology and Radiotherapy, Docrates Cancer Center, 00180 Helsinki, Finland; \\ timo.joensuu@docrates.com \\ * Correspondence: kalevi.kairemo@gmail.com
}

check for

updates

Citation: Kairemo, K.; Kappadath, S.C.; Joensuu, T.; Macapinlac, H.A. A Retrospective Comparative Study of Sodium Fluoride (NaF-18)-PET/CT and Fluorocholine (F-18-CH) PET/CT in the Evaluation of Skeletal Metastases in Metastatic Prostate Cancer Using a Volumetric 3-D Radiomics Analysis. Diagnostics 2021, 11, 17. https:/ /dx.doi. org/10.3390/diagnostics11010017

Received: 14 December 2020

Accepted: 21 December 2020

Published: 24 December 2020

Publisher's Note: MDPI stays neutral with regard to jurisdictional claims in published maps and institutional affiliations.

Copyright: () 2020 by the authors. Licensee MDPI, Basel, Switzerland. This article is an open access article distributed under the terms and conditions of the Creative Commons Attribution (CC BY) license (https: / / creativecommons.org/ licenses/by/4.0/).

\begin{abstract}
Bone metastases are common in prostate cancer (PCa). Fluorocholine-18 (FCH) and sodium fluoride-18 (NaF) have been used to assess PCa associated skeletal disease in thousands of patients by demonstrating different mechanism of uptake-cell membrane (lipid) synthesis and bone mineralization. Here, this difference is characterized quantitatively in detail. Our study cohort consisted of 12 patients with advanced disease (> 5 lesions) $(\mathrm{M})$ and of five PCa patients with no skeletal disease (N). They had routine PET/CT with FCH and $\mathrm{NaF}$ on consecutive days. Skeletal regions in CT were used to co-register the two PET/CT scans. Bone 3-D volume of interest (VOI) was defined on the CT of PET with a threshold of $\mathrm{HU}>150$, and sclerotic/dense bone as $\mathrm{HU}>600$, respectively. Additional VOIs were defined on PET uptake with the threshold values on both FCH (SUV > 3.5) and $\mathrm{NaF}$ (SUV > 10). The pathologic skeletal volumes for each technique (CT, HU > 600), $\mathrm{NaF}(\mathrm{SUV}>10)$ and FCH (SUV > 3.5) were developed and analyzed. The skeletal VOIs varied from $5.03 \mathrm{~L}$ to $7.31 \mathrm{~L}$, whereas sclerotic bone VOIs were from $0.88 \mathrm{~L}$ to $2.99 \mathrm{~L}$. Total choline kinase (cell membrane synthesis) activity for FCH (TCA) varied from 0.008 to 4.85 [kg] in M group and from 0.0006 to $0.085[\mathrm{~kg}]$ in $\mathrm{N}$ group. Total accelerated osteoblastic (bone demineralization) activity for $\mathrm{NaF}$ (TBA varied from 0.25 to 13.6 [kg] in M group and varied from 0.000 to 1.09 [kg] in N group. The sclerotic bone volume represented only $1.86 \pm 1.71 \%$ of the pathologic $\mathrm{FCH}$ volume and $4.07 \pm 3.21 \%$ of the pathologic $\mathrm{NaF}$ volume in M group, and only $0.08 \pm 0.09 \%$ and $0.18 \pm 0.19 \%$ in $\mathrm{N}$ group, respectively. Our results suggest that $\mathrm{CT}$ alone cannot be used for the assessment of the extent of active metastatic skeletal disease in $\mathrm{PCa}$. $\mathrm{NaF}$ and $\mathrm{FCH}$ give complementary information about the activity of the skeletal disease, improving diagnosis and disease staging.
\end{abstract}

Keywords: fluorocholine; sodium fluoride; positron emission tomography; prostate cancer; bone metastases; radiomics

\section{Introduction}

Prostate cancer (PCa) is the second most common male cancer and bone is the most frequent metastatic site. Approximately $10-30 \%$ of men with prostate cancer will present with incurable advanced or metastatic disease. Patients who develop metastatic disease are commonly treated with luteinizing hormone-releasing hormone agonist/antagonist therapy, which frequently leads to tumor regression [1,2]. Unfortunately, these regressions are typically transient, with an eventual tumor regrowth as castration-resistant disease 
that is invariably fatal [3]. Median survival in patients who develop metastatic castrationresistant prostate cancer (mCRPC) in the modern era is approximately two years [4]. One is the most frequent metastatic site in prostate cancer, with approximately $90 \%$ of patients with $\mathrm{mCRPC}$ having radiological evidence of bone metastases [5]. Unlike deaths from many other types of cancer, deaths from prostate cancer are usually due to bone disease and its complications.

Fluorocholine is a common radiotracer, used especially in Europe. A high progression in cancer growth demands increased lipid synthesis for the formation of new cellular membranes: this stimulates choline transporter and the cellular uptake of choline. In the cells, choline is transformed into phosphotidylcholine (lecithin) [6]. Thus, the uptake of choline is reflecting cellular proliferation. Our systematic review in more than 3000 patients demonstrated that choline PET/CT in prostate cancer had the most clinical effect in patients with PSA recurrence [6].

Sodium fluoride-18 (NaF) is a common radiotracer as well. The Society for Nuclear Medicine and Molecular Imaging has published guidelines for ${ }^{18} \mathrm{~F}-\mathrm{NaF}$ PET/CT in the US [7]. ${ }^{18} \mathrm{~F}$ - (fluoride ion) is exchanged for $\mathrm{OH}$ - (hydroxide ion), meaning that the hydroxyapatite bone matrix is transformed into fluoroapatite. High uptake of ${ }^{18} \mathrm{~F}-\mathrm{NaF}$ reflects bone reactions to skeletal disease, not necessarily reactions to cancer. Therefore, positive findings with ${ }^{18} \mathrm{~F}-\mathrm{NaF}$ PET /CT may be due to both benign and malignant bone disorders. The uptake of ${ }^{18} \mathrm{~F}-\mathrm{NaF}$ is part of the mineralization of bone matrix, and thus bone uptake of ${ }^{18} \mathrm{~F}-\mathrm{NaF}$ reflects bone remodeling. Patients with positive ${ }^{18} \mathrm{~F}-\mathrm{NaF}$ PET/CT scans have a high risk to develop bone metastases. In a systematic review, ${ }^{18} \mathrm{~F}-\mathrm{NaF}$ PET/CT 1289 (33\%) patients out of 3918 patients had positive scans [8].

It is important to characterize active skeletal metastatic disease in prostate cancer. Fluorocholine-18 $(\mathrm{FCH})$ and sodium fluoride-18 $(\mathrm{NaF})$ are registered radiopharmaceuticals in more than $15 \mathrm{EU}$ countries that have been used to assess PCa and associated bone metastases in several thousands of patients. The aim of this study was to analyze the role of FCH-PET, NaF-PET and CT simultaneously in advanced metastatic skeletal disease.

\section{Materials and Methods}

\subsection{Patients}

Prostate cancers were diagnosed between 1999 and 2015. In this retrospective one institute analysis we included all those patients who had both $\left[{ }^{18} \mathrm{~F}\right]-\mathrm{NaF}-\mathrm{PET}$ and $\left[{ }^{18} \mathrm{~F}\right]-$ fluorocholine-PET as a part of clinical staging on consecutive days as a part of their diagnostic program.

\subsubsection{Group}

Twelve new consecutive patients were analyzed between August 2015-December 2015 without any further selection. Men's ages ranged from 57 to 86 years; Gleason scores were 6-10; initial PSA values varied from 9.8 to $790 \mu \mathrm{g} / \mathrm{L}$, and all patients had T3-T4 disease. In addition, all patients had skeletal metastases, and three of them had visceral metastases. At Docrates Cancer Center in Helsinki, the radiological TNM staging was performed using $\left[{ }^{18} \mathrm{~F}\right]-\mathrm{NaF}-\mathrm{PET}$ and $\left[{ }^{18} \mathrm{~F}\right]$-fluorocholine-PET in all patients; most (10 out of 12) of the patients also had pelvic MRI and diagnostic whole body CT. These patients had to have more than five identifiable active metastases on both PET studies (in order to confirm skeletal metastatic disease).

Three of them had previous surgery (2 RRP+1TURP), seven had previous radiotherapy, all 12 had androgen deprivation therapy (ADT), six patients had received chemotherapy, three had received Sm-153-EDTMP therapy and two Ra-223, and eight additionally received denosumab. The patient characteristics are summarized in Table 1 (Arabic numbers). 
Table 1. Patient characteristics. Age, Gleason score (GS), TNM classification, time of diagnosis, initial S-PSA, previous treatments, skeletal therapies and S-PSA at the time of analysis. Abbreviations: ADT-androgen deprivation, Chchemotherapy, Rx—radiotherapy, A—abiraterone, D—denosumab, Ra—radium-223, Sm-Sm-153, Z-zolendronate. Arabic numbers refer to patients with skeletal metastases $(\mathrm{M})$ and Roman numbers to patients with no skeletal disease (N).

\begin{tabular}{ccccccccc}
\hline No. & Age & GS & TNM & Dgn & iPSA & Previous Treatments & Bone Therapies & PSA at PET-CT \\
\hline $\mathbf{1}$ & 86 & 6 & T1cNxMx & I-04 & 9.8 & TURP, ADT & Rx, ADT & A, Z \\
$\mathbf{2}$ & 76 & 8 & T3NxM0 & & 400 & Rx, ADT, Ch & Z, Sm, D \\
$\mathbf{3}$ & 74 & 8 & T3N0M0 & X-11 & 126 & Rx, ADT, Ch & Rx, D, Sm, Ra \\
$\mathbf{4}$ & 57 & 10 & T3N0M1 & VII-13 & 790 & Rx, ADT & Rx, D \\
$\mathbf{5}$ & 85 & 9 & T3bN1M1 & IX-15 & 100 & ADT, Ch & D \\
$\mathbf{6}$ & 63 & 8 & T3NxM1 & IV-13 & 490 & ADT, Ch & Rx, D \\
$\mathbf{7}$ & 69 & $9(4+5)$ & T3bN1M1 & III-14 & 86.4 & RRP, ADT, Ch & D \\
$\mathbf{8}$ & 59 & $7(3+4)$ & T3bN0M0 & VI-10 & 13 & RRP, ADT, Ch & D \\
$\mathbf{9}$ & 76 & $7(3+4)$ & T2bN0M0 & IV-02 & 16 & & 153 \\
I & 61 & $7(3+4)$ & T1cN0M0 & XII-15 & 7.1 & ADT & 390 \\
$\mathbf{1 0}$ & 61 & 8 & T3aN0M1 & XI-15 & 244 & & 8 \\
$\mathbf{1 1}$ & 67 & $9(4+5)$ & T4N1M1 & XII-15 & 40 & & 40 \\
II & 70 & $7(4+3)$ & T3bN0M0 & XII-15 & 17.6 & & 17.6 \\
III & 70 & 6 & T3bN0M0 & XII-15 & 12.6 & ADT & 12.6 \\
IV & 93 & 5 & T1cN0M0 & III-99 & 10.5 & & 26 \\
V & 76 & $7(4+3)$ & T4N0M0 & XII-15 & 73 & Rx, ADT, Ch & Rx, D, Sm, Ra \\
$\mathbf{1 2}$ & 50 & 9 & T4N1M1 & II-13 & 700 & 90.5 \\
\hline
\end{tabular}

\subsubsection{N Group}

Five patients with prostate cancer who had no skeletal metastases served as controls and their characteristics are summarized in Table 1 (Roman numbers). These were the five newest patients studied at the same time frame (the study order is shown in Table 1). Their radiological TNM staging or re-staging was performed using $\left[{ }^{18} \mathrm{~F}\right]-\mathrm{NaF}-\mathrm{PET}$ and $\left[{ }^{18} \mathrm{~F}\right]$-fluorocholine-PET on consecutive days. The men's ages ranged from 50 to 93 years; Gleason scores were 6-9; initial PSA values varied from 7.1 to $73 \mu \mathrm{g} / \mathrm{L}$, and these patients had T1c-T4 disease.

\subsection{Imaging PET/CT Protocol}

All the patients were studied for fluorocholine ${ }^{18} \mathrm{~F}-\mathrm{FCH}-\mathrm{PET} / \mathrm{CT}$ at Docrates Cancer Center using TruePoint PET-CT (Siemens Biograph 6, Erlangen, Germany). Patients were injected with ${ }^{18} \mathrm{~F}-\mathrm{FCH}$, using an average activity of $280 \mathrm{MBq}$ (range $210-402 \mathrm{MBq}$ ). Imaging was done in two phases, early whole body imaging at an average time of $11 \pm 4 \mathrm{~min}$ post injection, and late imaging of the pelvis at an average time of $64 \pm 5$ min post injection. Whole body imaging covered the area from the calvarium to the mid-thighs.

For sodium fluoride $\left(\mathrm{Na}^{18} \mathrm{~F}\right)$-PET/CT imaging was performed at $62 \mathrm{~min}$ (range $58-76 \mathrm{~min}$ ) as a whole body imaging (from the calvarium to the tips of toes) with an average activity of $222 \mathrm{MBq}$ (range 192 to $251 \mathrm{MBq}$ ).

Image data sets are FCH PET/CT with nominal administered activity $280 \mathrm{MBq}$, uptake time $60 \mathrm{~min}$, and scan range apex to mid-thigh. Image data sets also include NaF PET/CT with nominal administered activity $220 \mathrm{MBq}$, uptake time $60 \mathrm{~min}$, and whole body scan range. Both PET/CT scans were performed on the same PET/CT scanner within 1 day of each other. 17 patients were analyzed in this work-12 patients with skeletal metastases and 5 patients with no metastases.

Both tracers were used under special permission from the Finnish Medical Evaluation Agency (FiMEA). The tracers were manufactured and supplied by MAP Medical Technologies Oy, Tikkakoski, Finland. 


\subsection{Image Aanalysis}

Image segmentation for evaluation of functional volumes were performed using MIM Maestro v6.5 (MIM Software Inc., Cleveland, OH, USA). The image analysis processing steps were as follows:

1. The skeleton VOI was segmented by selecting voxels with $\mathrm{HU}>150$ on the CT scans from FCH and NaF PET/CT scans

2. A rigid registration of the two skeleton VOIs from FCH PET/CT and NaF PET/CT scans was performed. Now the two PET and CT scans are spatially co-registered in a single frame of reference. The skeleton VOI was labeled as "Skeleton" for figures.

3. A subset VOI of sclerotic (pathologic) bone was created by selecting voxels with $\mathrm{HU}>600$ within the skeleton VOI-labeled as "Skeleton 600".

4. A PET based VOI labeled "FCH PET 3.5" was created that is the fusion of voxels with FCH PET SUVbw > 3.5 and the "Skeleton" VOI.

5. A PET based VOI labeled "NaF PET 10" was created that is the fusion of voxels with $\mathrm{NaF}$ PET SUVbw > 10 and the "Skeleton" VOI.

6. A PET based VOI labeled "NaF $10 \mathrm{FCH} 3.5$ " was the fusion of "FCH PET 3.5" VOI and "NaF PET 10" VOI.

7. A PET based VOI labeled "Scl FCH 3.5" was the fusion of "FCH PET 3.5" VOI and "Skeleton 600" VOI.

8. A PET based VOI labeled "Scl NaF 10" was the fusion of "NaF PET 10" VOI and "Skeleton 600" VOI.

9. A PET based VOI labeled "Scl NaF $10 \mathrm{FCH}$ 3.5" was the fusion of "Scl FCH 3.5" VOI and "Scl NaF 10" VOI.

In summary, we created eight VOIs for each patient based on spatially co-registered FCH PET/CT and NaF PET/CT scans; namely, "Skeleton", "Skeleton 600", "FCH PET 3.5", "NaF PET 10", “NaF 10 FCH 3.5", "Scl FCH 3.5”, "Scl NaF 10", and "Scl NaF 10 FCH 3.5". For each VOI we computed the VOI volume (in $\mathrm{ml}$ ). The thresholds for skeleton (HU > 150) and dense bone (sclerosis) $(\mathrm{HU}>600)$ were determined from the $\mathrm{CT}$ component of the PET/CT study and were based on experience in more than 500 PET/CT studies. The pathologic FCH value (SUV > 3.5) was based on experience in more than $300 \mathrm{FCH} / \mathrm{PET}$ studies to indicate a pathological uptake. Tha pathological NaF value (SUV > 10) was similarly based on individual experience, but it was the same as the MDACC TFL 10 criteria presented in the literature [9].

In addition to the PET based VOIs, we computed metrics analogous to total lesion glycolysis (TLG) in FDG PET scans. For the FCH PET based VOIs, the product of the VOI volume and the mean SUVbw in "FCH PET 3.5" and "Scl FCH 3.5" corresponds to the total cell membrane synthesis activity (TCA) in bone and sclerotic bone, respectively. For the NaF PET based VOIs, the product of the VOI volume and the mean SUVbw in "NaF PET 10 " and "Scl NaF 10" corresponds to the total bone demineralization (TBA) in bone and sclerotic bone, respectively. An example of the patient analysis is shown in Figure 1.

The percentage volumes of "Skeleton 600", "FCH PET 3.5", "NaF PET 10", and "NaF $10 \mathrm{FCH} 3.5$ " with respect to "Skeleton" were calculated. Similarly, the percentage volumes of "Scl FCH 3.5", "Scl NaF 10", and "Scl NaF $10 \mathrm{FCH}$ 3.5" with respect to "Skeleton 600" was calculated. The mean, minimum, and maximum of the percentage volumes were calculated. The ratio of mean percentage volumes between abnormal and normal patients were calculated. A student's t-test was performed between the percentage volumes for abnormal and normal patients. 


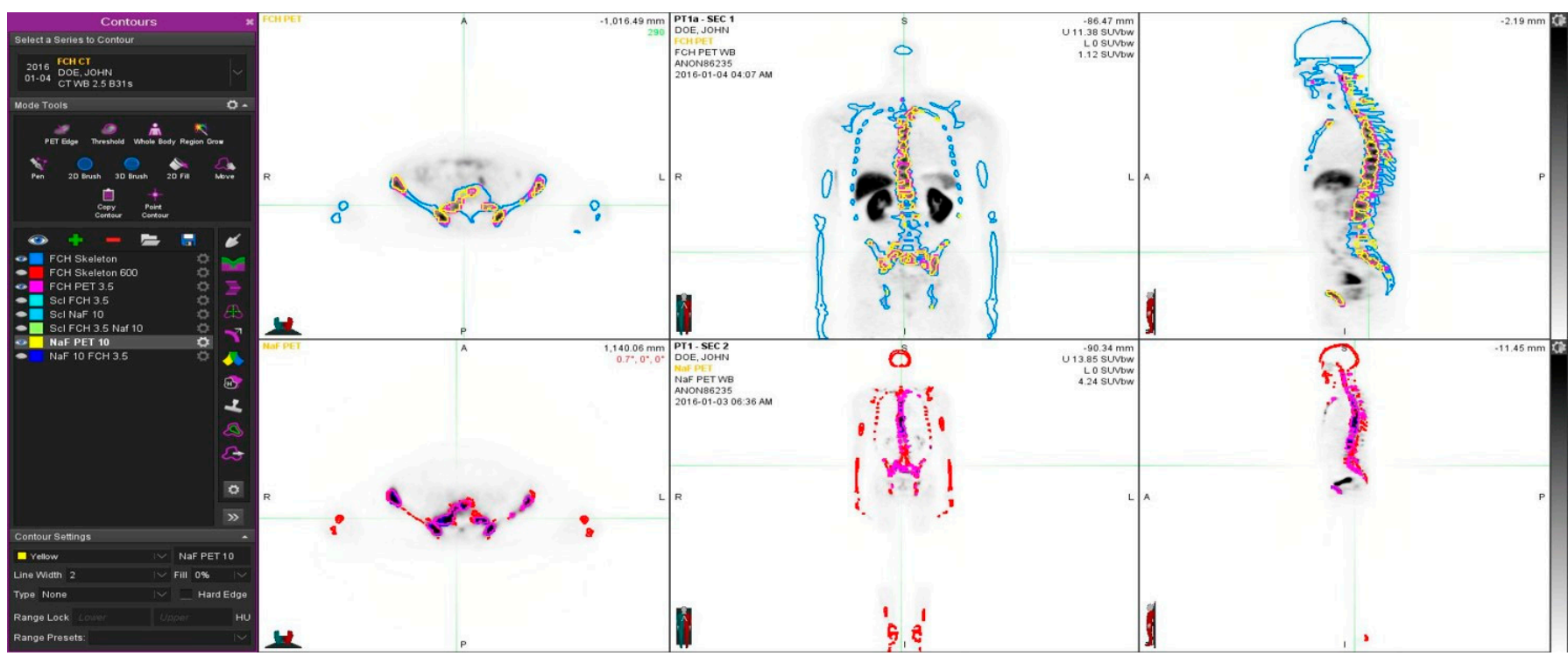

Figure 1. Example of a patient study (pt 11, Table 1). This 67-year old patient had an aggressive prostate cancer, T4N1M1 when initially diagnosed with Gleason score 9. S-PSA was 40. The upper row shows FCH PET study one transaxial, coronal and sagittal section. The lower row illustrates the same sections in the NaF PET study. Here, normal skeleton (HU > 150 as measured from simultaneous CT) is shown in red on NaF PET (lower row) and blue on FCH PET (upper row). Pathologic $\mathrm{NaF}(\mathrm{SUV}>10)$ is shown in yellow on FCH PET (upper row) and pathologic FCH (SUV > 3.5) in purple on NaF PET (lower row). This demonstrates clearly that volume regions differ significantly from each other, and PET tracers show different distributions, i.e., $\mathrm{NaF}$ is targeting cortical bone and $\mathrm{FCH}$ bone marrow.

\section{Results}

Our cohort consisted of twelve patients with advanced disease ( $>5$ lesions) who had had routine PET/CT both with FCH and NaF on consecutive days. An example is given in Figure 1.

The patient characteristics are summarized in Table 1. For comparison, we had five patients diagnosed with prostate cancer who did not have skeletal disease (Table 1).

Our results demonstrate that the skeletal VOI volumes varied from $5.03 \mathrm{~L}$ to $7.31 \mathrm{~L}$ in patients with skeletal metastases $(n=12)$, whereas sclerotic bone volumes were from $0.88 \mathrm{~L}$ to $2.99 \mathrm{~L}$. The sclerotic bone volume was $20.5 \pm 6.8 \%$ of skeletal volume (this was defined by FCH-PET).

In control prostate cancer patients without skeletal metastases, the skeletal VOI volumes varied from $4.60 \mathrm{~L}$ to $7.90 \mathrm{~L}(n=5)$, and sclerotic bone volumes were from $1.02 \mathrm{~L}$ to 1.76 L. The sclerotic bone volume was $19.9 \pm 4.4 \%$ of skeletal volume.

The TCA varied from 0.008 to 4.85 [kg] in patients with skeletal metastases and varied from 0.0006 to 0.085 [kg] in PCa control patients with no metastases. The TBA varied from 0.25 to $13.6[\mathrm{~kg}]$ in patients with skeletal metastases and varied from 0.000 to 1.09 [kg] in PCa control patients.

The sclerotic bone volume represented only $1.86 \pm 1.71 \%$ of the pathologic FCH volume and $4.07 \pm 3.21 \%$ of the $\mathrm{TLF}_{10}(\mathrm{SUVmax}>10)$ in patients with multiple metastases. In the control PCa, patients pathologic FCH was only $0.08 \pm 0.09 \%$ of the sclerotic bone volume $(p<0.004)$ and pathologic NaF volume $0.18 \pm 0.19 \%$ of sclerotic bone $(p<0.001)$. All the differences between the metastasis group and control cancer patient group are shown in Table 2. 
Table 2. Results. Pathologic PET/CT volumes as percentages of the skeletal volumes (when HU $>150$ on CT) are presented. Pathologic volumes for FCH (SUV > 3.5), NaF (SUV > 10) and when both are pathologic on PET studies are shown. Sclerosis is measured from CT (HU > 600) volume and calculated from FCH PET/CT. Similarly, simultaneous sclerosis and pathologic volumes for both FCH and/or NaF are shown. The volumes are shown for patients with bone metastases (M) and for control prostate cancer patients with no skeletal metastases (N). The amount of sclerosis does not statistically differ in these patient groups. All pathological volumes differ statistically significantly from each other between $\mathrm{M}$ and $\mathrm{N}$ group.

\begin{tabular}{|c|c|c|c|c|c|c|c|}
\hline & $\begin{array}{l}\text { FCH-PET } \\
(\mathrm{SUV}>3.5)\end{array}$ & $\begin{array}{l}\text { NaF-PET } \\
(\mathrm{SUV}>10)\end{array}$ & $\begin{array}{l}\text { FCH- \& NaF-PET } \\
(\text { SUV }>3.5 \&>10)\end{array}$ & $\begin{array}{l}\text { Sclerosis on CT } \\
\quad(H U>600)\end{array}$ & $\begin{array}{c}\text { Sclerosis \& FCH } \\
(\mathrm{HU}>600 \& \text { SUV }>3.5)\end{array}$ & $\begin{array}{c}\text { Sclerosis \& NaF } \\
(\mathrm{HU}>600 \text { \& SUV > 10) }\end{array}$ & $\begin{array}{c}\text { Sclerosis \& FCH \& NaF } \\
(\mathrm{HU}>600 \text { \& SUV }>3.5 \&>10)\end{array}$ \\
\hline Skeletal mets $(n=12)$ & $4.8 \pm 5.7 \%$ & $6.1 \pm 5.5 \%$ & $2.8 \pm 3.2 \%$ & $20.5 \pm 6.8 \%$ & $1.9 \pm 1.7 \%$ & $4.1 \pm 3.2 \%$ & $1.1 \pm 1.0 \%$ \\
\hline PCa with no mets $(n=5)$ & $0.11 \pm 0.11 \%$ & $0.55 \pm 0.57 \%$ & $0.00 \pm 0.00 \%$ & $19.9 \pm 4.3 \%$ & $0.08 \pm 0.09 \%$ & $0.18 \pm 0.19 \%$ & $0.00 \pm 0.00 \%$ \\
\hline$p$-value & $<0.017$ & $<0.005$ & $<0.013$ & 0.843 & $<0.004$ & $<0.001$ & $<0.002$ \\
\hline
\end{tabular}


Table 2 summarizes pathologic PET/CT volumes as percentages of the skeletal volumes (when HU > 150 on CT). Pathologic volumes for FCH (SUV >3.5), NaF (SUV > 10) and when both were pathologic on PET were larger in patients with metastases as compared to patients with no metastases. Sclerosis as measured from CT $(\mathrm{HU}>600)$ and this in combination with pathologic FCH (SUV >3.5) and NaF concentrations (SUV > 10) were similarly larger in patients with metastases. All the differences were statistically significant (Table 2).

Figure 2 demonstrates a young prostate cancer patient (50-year-old) with aggressive prostate cancer, and T4N1M1 with an initial PSA 700 and a Gleason score 9. He was treated with radiation therapy, hormonal therapy, chemotherapy and multiple targeted bone therapies, including two radionuclide therapies. In spite of this, the PET volume regions differed significantly from each other, and PET tracers show different distributions. Fluoride typically targets cortical bone and bone formation, whereas choline targets active proliferative cancer cells, preferably bone marrow. The tiny overlapping regions can be seen in Figure 2, especially in the transaxial image.

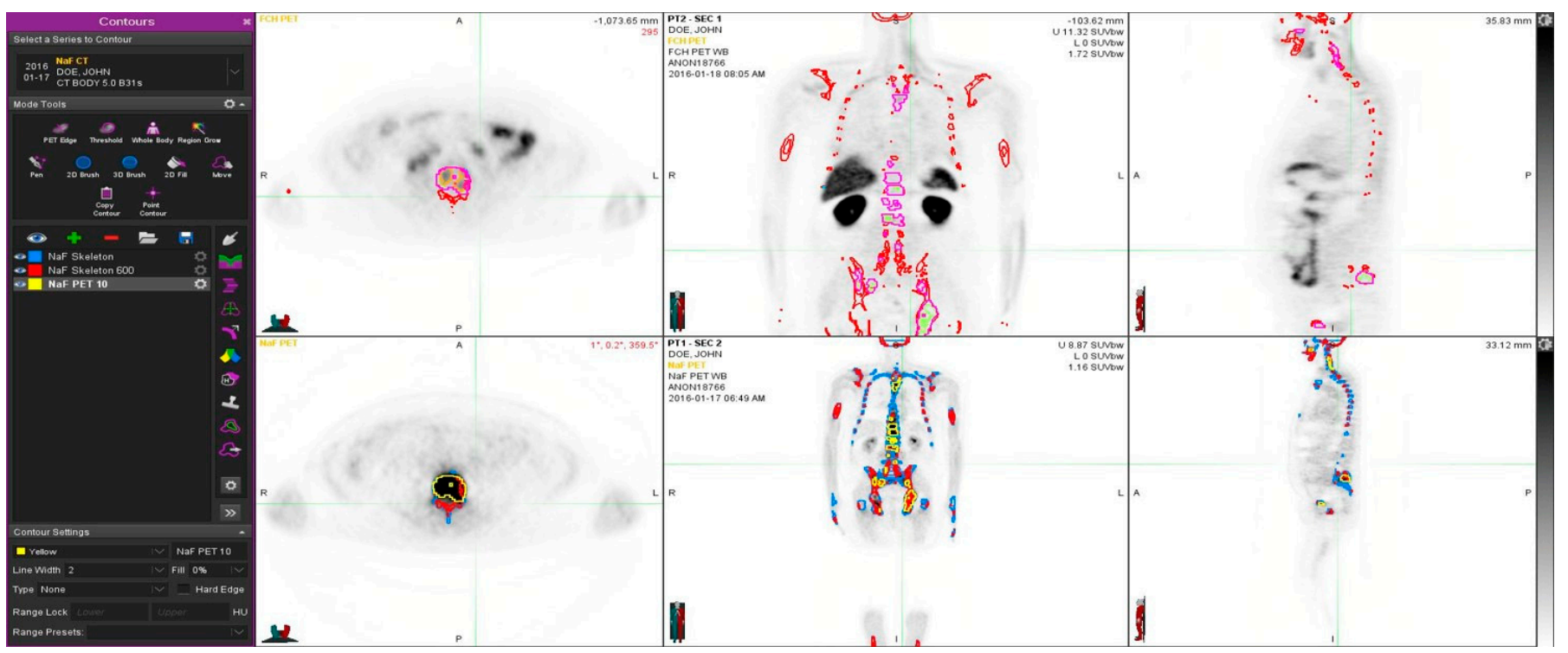

Figure 2. Example of a patient study (pt 12, Table 1). This 50-year old patient had an aggressive prostate cancer, T4N1M1 with initial PSA 700 and Gleason score 9. He was treated with radiation therapy, hormonal therapy, chemotherapy and multiple targeted bone therapies. At the time of the imagings S-PSA was 90. The upper row shows FCH PET study one transaxial, coronal and sagittal section. The lower row illustrates the same sections in the NaF PET study. Here, normal skeleton (HU > 150, as measured from simultaneous CT), is shown in blue on NaF PET (lower row). Sclerotic bone $(\mathrm{HU}>600)$ is shown in red in all images. Pathologic NaF (SUV > 10) is shown in yellow (lower row) on NaF PET and in purple on FCH PET (upper row). This demonstrates clearly that volume regions differ significantly from each other, and PET tracers show different distributions.

There was a correlation between TCA and S-PSA $(p<0.020)$, but TBA and total sclerotic bone did not correlate with S-PSA. Figure $3 \mathrm{a}-\mathrm{c}$ show the correlations. 


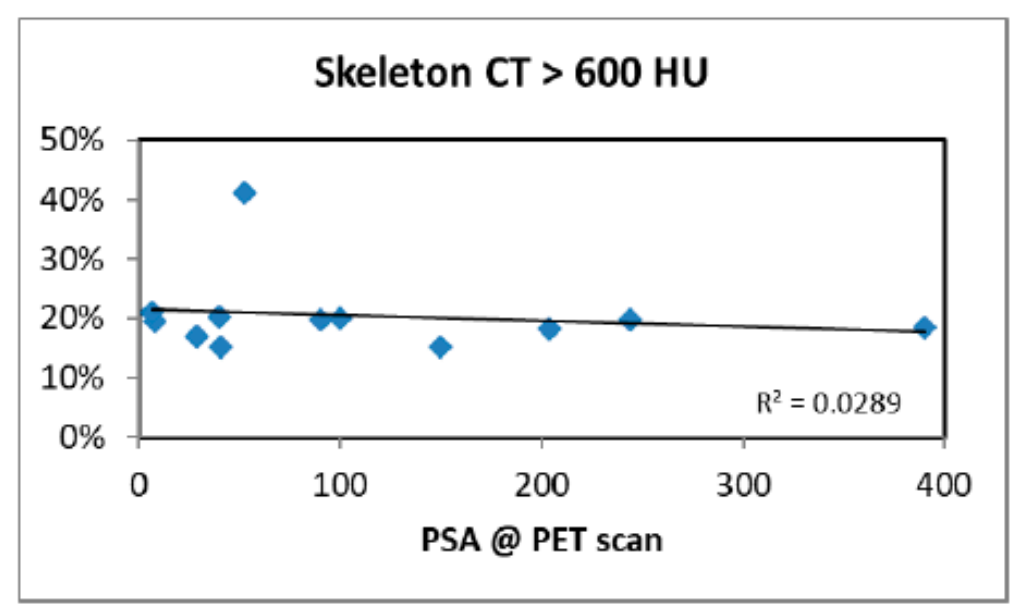

(a)

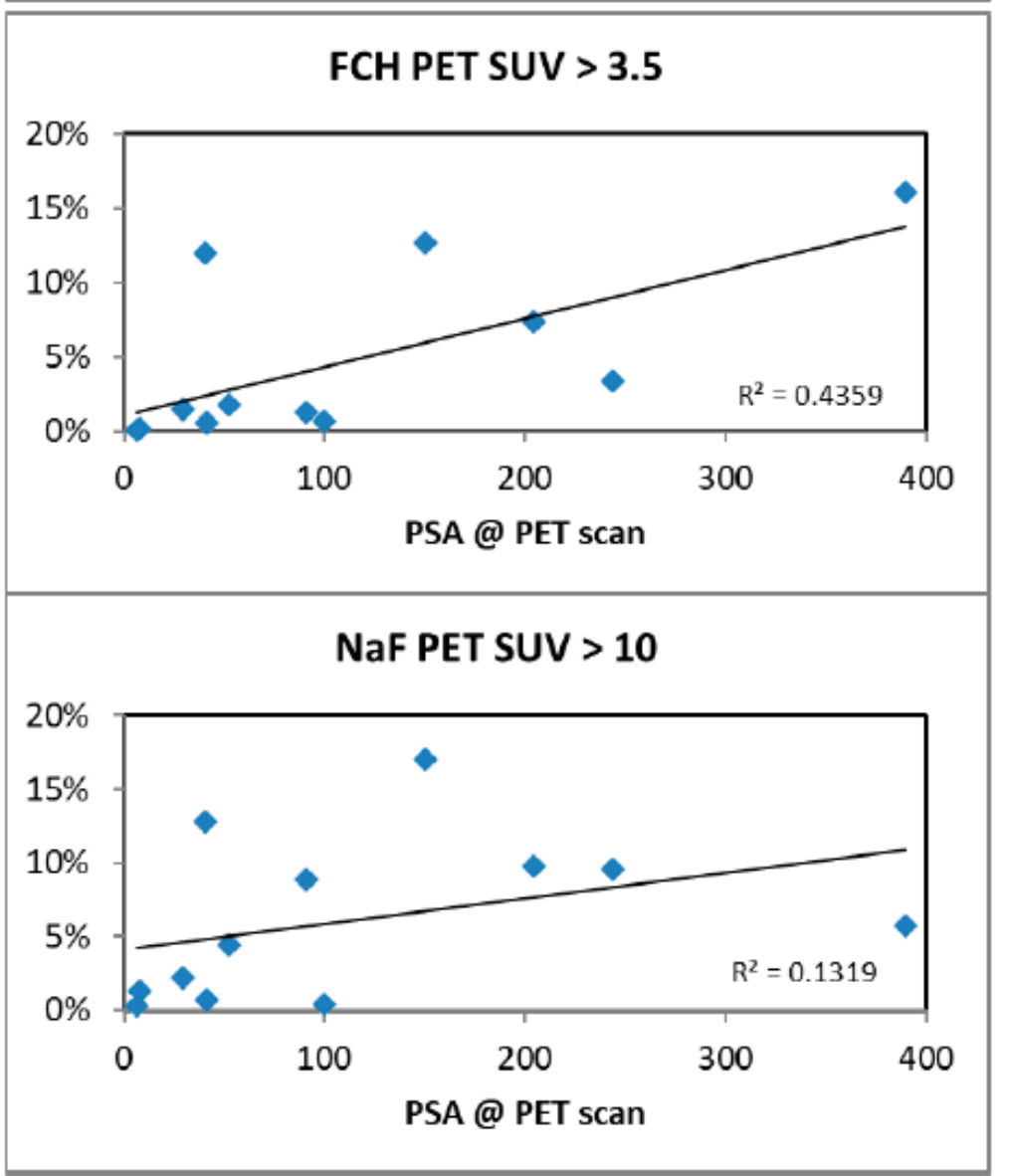

(b)

(c)

Figure 3. Volumes of sclerosis $(\mathrm{HU}>600)(\mathbf{a})$, total choline kinase activity (SUV > 3.5 on FCH PET) (b) and total bone demineralization activity (SUV > 10 on NaF PET) vs. serum PSA (c). PSA correlated with total choline kinase activity $(p<0.02)$. PSA did not correlate with the amount of sclerosis seen on CT $(p>0.5)$ nor with the bone demineralization activity $(p>0.2)$. S-PSA is presented as $\mathrm{ng} / \mathrm{mL}$ and volumes as percentages of total skeletal volume.

\section{Discussion}

In this study we analyzed of FCH-PET, NaF-PET and CT at the same time in advanced metastatic skeletal disease. NaF-PET/CT was performed in one session and FCH/PET-CT on the following day, the PET studies were then fixed with each other with the use of the skeletal CT. Due to this, the skeleton will not change substantially in one day, and this allows for the overlap of FCH-PET and NaF-PET three-dimensionally and the possibility of analyzing the regional differences in detail. 
There was no difference in the amount of sclerosis in our patient groups, the sclerotic bone volume was $20.5 \pm 6.77 \%$ of skeletal volume, as defined by FCH-PET in patients with bone metastases $(\mathrm{M})$, and $19.9 \pm 4.43 \%$ of skeletal volume in control prostate cancer patients without skeletal metastases $(\mathrm{N})$. The sclerotic bone volume was defined from the CT measurements using Hounsfield Unit criteria, $\mathrm{HU}>600$. This indicates that the patient populations could be compared with each other for other skeletal phenomena because the degenerative changes were in the same level in both patient populations. The sclerotic volume ranges were from $0.88 \mathrm{~L}$ to $2.99 \mathrm{~L}$ in the metastatic group and from $1.02 \mathrm{~L}$ to $1.76 \mathrm{~L}$ in control patients without bone metastases.

We developed new parameters (analogous to TLG, total lesion glycolysis for ${ }^{18}$ FDGPET) as total choline kinase activity (total cell membrane synthesis activity) for FCH (TCA) and total accelerated osteoblastic activity (total bone demineralization) activity for $\mathrm{NaF}$ (TBA). The respective volumes of the whole skeletal volume are shown as Venn-Diagrams in Figure 4.

\section{PCa with skeletal metastases}

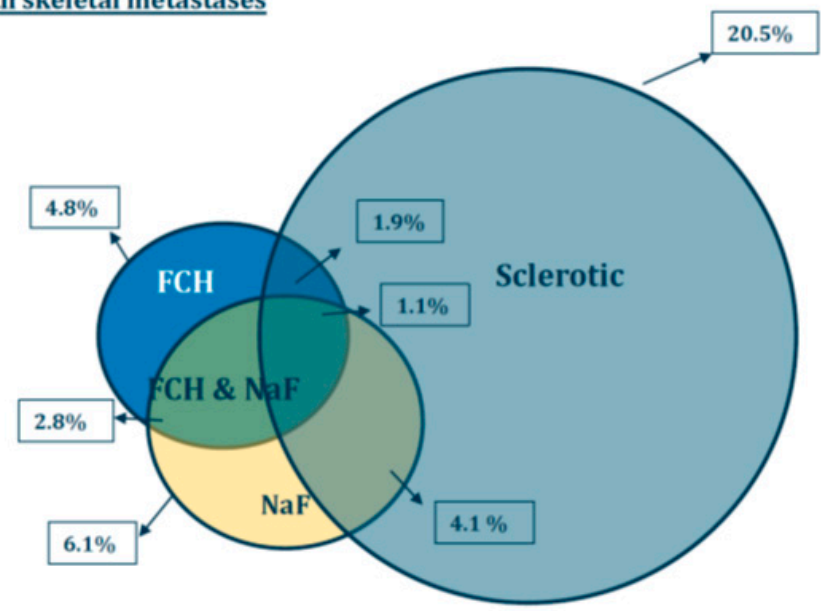

PCa with no metastases

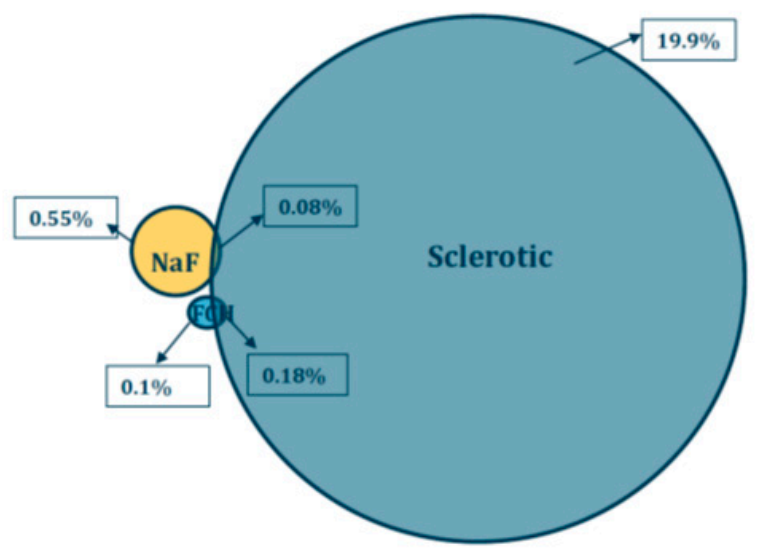

Figure 4. Pathologic PET/CT volumes as percentages of the skeletal volumes (when HU > 150 on CT) are presented as spheres. Pathologic volumes for FCH (SUV > 3.5) are in blue and NaF (SUV > 10) in yellow. Sclerosis is measured from CT $(\mathrm{HU}>600)$ volume (grey). The volumes are shown for patients with bone metastases $(\mathrm{M})$ and for control prostate cancer patients with no skeletal metastases $(\mathrm{N})$. The amount of sclerosis (grey spheres) does not statistically differ in these patient groups. All pathological volumes, including overlapping regions, differ statistically significantly from each other between $\mathrm{M}$ and $\mathrm{N}$ group.

The differences are seen easily from the Figure 4. The pathologic PET variables, i.e., $\mathrm{FCH}$ (blue) and $\mathrm{NaF}$ (yellow) volumes differ significantly from each other, eventhough there is an overlapping region $(2.8 \%)$ in patients with skeletal metastases. In control prostate cancer patients (with no skeletal metastases), these regions did not overlap. In clinical practice, this means that these methods measure different phenomena.

The diagnostic accuracy of ${ }^{18} \mathrm{~F}$-Choline PET/CT is improved by use of both early and late imaging [10]. An article analyzing 300 patients found that $48(16 \%)$ had false-positive results [11]. False positive findings were listed: in the prostate may be related to prostatitis and intraepithelial neoplasia; in lymph nodes to lymphadenitis; and in distant organs to other neoplasms. Evangelista et al. [12] found a sensitivity of $49 \%$ and a specificity of $95 \%$ in a systematic review. Androgen deprivation therapy (ADT) may reduce choline uptake in PET scans [13,14], but some studies did not find a reduction associated with ADT [14,15]. Choline PET/CT-positive patients had a poorer survival than PET/CT-negative patients, indicating that it is a prognostic factor [16-18]. In a systematic analysis, of 938 patients, $381(41 \%)$ had positive radiolabeled choline PET/CT scans and a change of treatment, and after the change of treatment, $101(25 \%)$ of 404 patients had a complete PSA response [6]. In a study consisting of 58 patients, it was stated that FCH PET/CT should be preferred to 
CT and bone scintigraphy in patients with prostate cancer with bone metastases, because it allows for a better stratification of time to progression, skeletal event free survival and cancer specific survival [19].

Our own experience with FCH PET false-positive findings associate with myeloproliferative medication in these patients with advanced and aggressive metastatic prostate cancer, such as GM-CSF treatment. In the literature, a case is presented about FCH PET/CT in a patient with biochemical recurrent prostate cancer who was receiving erythropoietin for hemochromatosis. Only diffuse skeletal uptake of FCH was seen. ${ }^{18}$ F-Fluoride PET/CT performed the following day demonstrated multiple abnormal focal bone metastases [20]. This is the way we analyzed all these patients: two PET studies on consecutive days. Theoretically, widespread diffuse metastazing configuration could be missed, if the judgement would be based on a single PET study. Sometimes PCa can be PSA negative, and negative PET findings occur with both $\mathrm{NaF}$ and FCH [21-23]. Two PET studies were used routinely in the diagnosis of prostate cancer in our institution. Earlier it was $\mathrm{NaF}$ and FCH on consecutive days, because they gave complementary information. In Figure 4, the intersection of $\mathrm{NaF}$ and $\mathrm{FCH}$ (green area) represents the same volume; what is seen either in blue or yellow is complementary information. Today, it could also be PSMA-PET and FDG-PET in order to identify those patients who do not necessarily respond to targeted therapies, such as PSMA targeted therapies [24]. With this NaF and FCH approach, we could select patients who benefit from bone targeting therapies, such as Ra-223 and select patients who might benefit from antiproliferative chemotherapy.

The data from US National Oncologic PET Registry demonstrates that the indication for the PET/CT reflects PET/CT findings: $14 \%$ of patients had a positive ${ }^{18} \mathrm{~F}-\mathrm{NaF}$ PET/CT at staging; $29 \%$ of the patients had positive ${ }^{18} \mathrm{~F}-\mathrm{NaF}$ PET/CT if the examination was an initial test for bone metastases; $76 \%$ of the patients had positive ${ }^{18} \mathrm{~F}-\mathrm{NaF}$ PET $/ \mathrm{CT}$ if the examination was requested as a test for progressive bone metastases [8]. ${ }^{18} \mathrm{~F}-\mathrm{NaF}$ and ${ }^{18} \mathrm{~F}$-Choline PET/CT show similar diagnostic accuracy at staging for patients with prostate cancer, but ${ }^{18} \mathrm{~F}$-Choline has higher specificity at restaging for recurrence [21]. Sodium fluoride suits for follow-up of PCa with skeletal metastases [25-27] and even for quantitative assessment of treatment response [28]. In fact, quantitative criteria have been developed [29].

This dual tracer method improves diagnostics. Bone metastases are formed by hematogenic spread; therefore, the assessment of bone marrow and cortical bone separately is a clear benefit. This radiomics evaluation utilizing rigid skeleton to fix two PET studies is a new method that makes volumetric evaluations possible. Theoretically, it enables a new possibility for the detection of bone marrow/cortex interface activity. In spite of the limited number of patients, 17 total, we could find in almost every patient small areas of FCH and NaF concentrations, which did not overlap. These should be characterized in detail in larger populations because bone sampling is impossible. Even though our findings are very statistically significant, the small number of patients may have an effect on results. Nevertheless, we have shown here identical results in a patient who was treatment naively (Figure 1) and in a patient who was heavily treated, including targeted bone therapies (Figure 2); in both patients with $\mathrm{T}_{4} \mathrm{~N}_{1} \mathrm{M}_{1}$ disease, the methods gave similar complementary information. There are multiple options for PET tracer selection in prostate cancer [30]. This dual tracer combination for volumetric radiomics analysis seems to be excellent, but other alternatives should be tested in clinical trials; PSMA is an important new target.

\section{Conclusions}

From this study, we can conclude that CT is not well suited for assessing active skeletal metastases in an aggressive prostate cancer (T3-4 disease). Both NaF and FCH are useful in the evaluation of active skeletal metastatic disease, but they measure different phenomena and definitely give complementary information. Furthermore, FCH correlates positively with serum PSA concentration and is thus probably a prognostic factor. 
Author Contributions: Conceptualization, K.K. and H.A.M.; methodology K.K. and S.C.K.; software K.K. and S.C.K.; validation, all authors; formal analysis, K.K., S.C.K., T.J.; investigation, all authors; resources T.J. and H.A.M. data curation, K.K. and S.C.K.; writing-original draft preparation, K.K.; writing-review and editing, all authors; visualization, K.K. and S.C.K.; supervision, K.K. and H.A.M.; project administration, K.K.; funding acquisition, T.J. and H.A.M. All authors have read and agreed to the published version of the manuscript. All authors contributed substantially to the work reported.

Funding: This research received no external funding.

Institutional Review Board Statement: This retrospective analysis was performed, according to the principles of the Declaration of Helsinki and our patient database was approved by the Finnish authority for the protection of privacy and personal data. These patients had both $\left[{ }^{18} \mathrm{~F}\right]-\mathrm{NaF}-\mathrm{PET}$ and $\left[{ }^{18} \mathrm{~F}\right]-$ fluorocholine-PET as part of the clinical staging on consecutive days of their diagnostic program. This study also had institutional approval for the unidentifiable data transfer. The quantitative analysis had separate approval from MDACC.

Informed Consent Statement: Informed consent was obtained from all subjects involved in the study.

Acknowledgments: Kalevi Kairemo received an International Best Abstract Award at the Society of Nuclear Medicine and Molecular Imaging Annual Congress for presenting this work.

Conflicts of Interest: The authors declare no conflict of interest.

\section{References}

1. Alva, A.; Hussain, M. The changing natural history of metastatic prostate cancer. Cancer J. 2013, 19, 19-24. [CrossRef] [PubMed]

2. Scher, H.I.; Sawyers, C.L. Biology of progressive, castration-resistant prostate cancer: Directed therapies targeting the androgenreceptor signaling axis. J. Clin. Oncol. 2005, 23, 8253-8261. [CrossRef] [PubMed]

3. Saad, F.; Hotte, S.J. Guidelines for the management of castrate-resistant prostate cancer. Can. Urol. Assoc. J. 2010, 4, 380-384. [CrossRef] [PubMed]

4. Sathiakumar, N.; Delzell, E.; Morrisey, M.A.; Falkson, C.; Yong, M.; Chia, V.; Blackburn, J.; Arora, T.; Kilgore, M.L. Mortality following bone metastasis and skeletal-related events among men with prostate cancer: A population-based analysis of US Medicare beneficiaries, 1999-2006. Prostate Cancer Prostatic Dis. 2011, 14, 177-183. [CrossRef] [PubMed]

5. Lange, P.H.; Vessella, R.L. Mechanisms, hypotheses and questions regarding prostate cancer micrometastases to bone. Cancer Metastasis Rev. 1999, 17, 331-336. [CrossRef]

6. von Eyben, F.E.; Kairemo, K. Meta-analysis of ${ }^{11} \mathrm{C}$-choline and ${ }^{18}$ F-choline PET/CT for management of patients with prostate cancer. Nucl. Med. Commun. 2014, 35, 221-230. [CrossRef]

7. Segall, G.; Delbeke, D.; Stabin, M.G.; Even-Sapir, E.; Fair, J.; Sajdak, R.; Smith, G.T. SNM practice guideline for sodium ${ }^{18}$ F-fluoride PET/CT bone scans 1.0. J. Nucl. Med. 2010, 51, 1813-1820. [CrossRef]

8. von Eyben, F.E.; Kairemo, K.; Kiljunen, T.; Joensuu, T. Planning of External Beam Radiotherapy for Prostate Cancer Guided by PET/CT. Curr. Radiopharm. 2015, 8, 19-31. [CrossRef]

9. Rohren, E.M.; Etchebehere, E.C.; Araujo, J.C.; Hobbs, B.P.; Swanson, N.M.; Everding, M.; Moody, T.; Macapinlac, A. Determination of Skeletal Tumor Burden on ${ }^{18}$ F-Fluoride PET/CT. J. Nucl. Med. 2015, 56, 1507-1512. [CrossRef]

10. Massaro, A.; Ferretti, A.; Secchiero, C.; Cittadin, S.; Milan, E.; Tamiso, L.; Pavan, L.; Tommasi, E.; Marzola, M.C.; Chondrogiannis, S. Optimising ${ }^{18} \mathrm{~F}-\mathrm{Choline} \mathrm{PET/CT} \mathrm{Acquisition} \mathrm{Protocol} \mathrm{in} \mathrm{Prostate} \mathrm{Cancer} \mathrm{Patients.} \mathrm{N.} \mathrm{Am.} \mathrm{J.} \mathrm{Med.} \mathrm{Sci.} \mathrm{2012,} \mathrm{4,} \mathrm{416-420.}$

11. Calabria, F.; Chiaravalloti, A.; Schillaci, O. ${ }^{18}$ F-choline PET/CT pitfalls in image interpretation: An update on 300 examined patients with prostate cancer. Clin. Nucl. Med. 2014, 39, 122-130. [CrossRef] [PubMed]

12. Evangelista, L.; Guttilla, A.; Zattoni, F.; Muzzio, P.C.; Zattoni, F. Utility of choline positron emission tomography/computed tomography for lymph node involvement identification in intermediate- to high-risk prostate cancer: A systematic literature review and meta-analysis. Eur. Urol. 2013, 63, 1040-1048. [CrossRef] [PubMed]

13. Dost, R.J.; Glaudemans, A.W.; Breeuwsma, A.J.; de Jong, I.J. Influence of androgen deprivation therapy on choline PET/CT in recurrent prostate cancer. Eur. J. Nucl. Med. Mol. Imaging 2013, 40 (Suppl. 1), S41-S47. [CrossRef] [PubMed]

14. Fuccio, C.; Schiavina, R.; Castellucci, P.; Rubello, D.; Martorana, G.; Celli, M.; Malizia, C.; Profitos, M.B.; Marzola, M.C.; Pettinato $\mathrm{V}$; et al. Androgen deprivation therapy influences the uptake of ${ }^{11} \mathrm{C}$-choline in patients with recurrent prostate cancer: The preliminary results of a sequential PET/CT study. Eur. J. Nucl. Med. Mol. Imaging 2011, 38, 1985-9198. [CrossRef]

15. Beheshti, M.; Haim, S.; Zakavi, R.; Steinmair, M.; Waldenberger, P.; Kunit, T.; Nader, M.; Langsteger, W.; Loidl, W. Impact of ${ }^{18}$ Fcholine PET/CT in prostate cancer patients with biochemical recurrence: Influence of androgen deprivation therapy and correlation with PSA kinetics. J. Nucl. Med. 2013, 54, 833-840. [CrossRef]

16. Chondrogiannis, S.; Marzola, M.C.; Ferretti, A.; Grassetto, G.; Maffione, A.M.; Rampin, L.; Fanti, S.; Giammarile, F.; Rubello, D. Is the detection rate of ${ }^{18} \mathrm{~F}$-choline PET/CT influenced byandrogen-deprivation therapy? Eur. J. Nucl. Med. Mol. Imaging 2014, 41, 1293-1300. [CrossRef] 
17. Giovacchini, G.; Picchio, M.; Garcia-Parra, R.; Briganti, A.; Abdollah, F.; Gianolli, L.; Schindler, C.; Montorsi, F.; Messa, C.; Fazio, F. ${ }^{11} \mathrm{C}$-choline PET/CT predicts prostate cancer-specific survival in patients with biochemical failure during androgen deprivation therapy. J. Nucl. Med. 2014, 55, 233-241. [CrossRef]

18. Reske, S.N.; Moritz, S.; Kull, T. $\left[{ }^{11} \mathrm{C}\right]$ Choline-PET/CT for outcome prediction of salvage radiotherapy of local relapsing prostate carcinoma. Q. J. Nucl. Med. Mol. Imaging 2012, 56, 430-439.

19. Zattoni, F.; Agostini, E.; Cattaneo, F.; Maruzzo, M.; Basso, U.; Zattoni, F.; Evangelista, L. Fluorocholine PET/CT predicts skeletal progression, skeletal event and cancer specific survival in patients with biochemical relapse for prostate cancer. Clin. Imaging 2017, 43, 110-116. [CrossRef]

20. Balogova, S.; Huchet, V.; Egrot, C.; Michaud, L.; Paycha, F.; Kerrou, K.; Montravers, F.; Cussenot, O.; Talbot, J.N. Effect of erythropoietin on bone marrow uptake of ${ }^{18} \mathrm{~F}$-fluorocholine in prostate cancer: Comparison with ${ }^{18} \mathrm{~F}$-fluoride uptake. Clin. Nucl. Med. 2013, 38, 200-202. [CrossRef]

21. Langsteger, W.; Balogova, S.; Huchet, V.; Beheshti, M.; Paycha, F.; Egrot, C.; Janetschek, G.; Loidl, W.; Nataf, V.; Kerrou, K. Fluorocholine $\left({ }^{18} \mathrm{~F}\right)$ and sodium fluoride $\left({ }^{18} \mathrm{~F}\right) \mathrm{PET} / \mathrm{CT}$ in the detection of prostate cancer: Prospective comparison of diagnostic performance determined by masked reading. Q. J. Nucl. Med. Mol. Imaging 2011, 55, 448-457. [PubMed]

22. Beheshti, M.; Vali, R.; Waldenberger, P.; Fitz, F.; Nader, M.; Loidl, W.; Broinger, G.; Stoiber, F.; Foglman, I.; Langsteger, W. Detection of bone metastases in patients with prostate cancer by ${ }^{18} \mathrm{~F}$ fluorocholine and ${ }^{18} \mathrm{~F}$ fluoride PET-CT: A comparative study. Eur. J. Nucl. Med. Mol. Imaging 2008, 35, 1766-1774. [CrossRef] [PubMed]

23. Kjolhede, H.; Ahlgren, G.; Almquist, H.; Liedberg, F.; Lyttkens, K.; Ohlsson, T.; Bratt, O. Combined ${ }^{18}$ F-fluorocholine and ${ }^{18}$ Ffluoride positron emission tomography/computed tomography imaging for staging of high-risk prostate cancer. BJU Int. 2012, 110, 1501-1506. [CrossRef] [PubMed]

24. Hofman, M.S.; Emmett, L.; Violet, J.; Zhang, A.Y.; Lawrence, N.J.; Stockler, M.; Francis, R.J.; Iravani, A.; Williams, S.; Azad, A.; et al. TheraP: A randomized phase 2 trial of (177) Lu-PSMA-617 theranostic treatment vs cabazitaxel in progressive metastatic castration-resistant prostate cancer (Clinical Trial Protocol ANZUP 1603). BJU Int. 2019, 124 (Suppl. 1), 5-13. [CrossRef] [PubMed]

25. Even-Sapir, E.; Metser, U.; Mishani, E.; Lievshitz, G.; Lerman, H.; Leibovitch, I. The detection of bone metastases in patients with high-risk prostate cancer: ${ }^{99 \mathrm{~m}} \mathrm{Tc}-\mathrm{MDP}$ Planar bone scintigraphy, single- and multi-field-of-view SPECT, ${ }^{18} \mathrm{~F}-\mathrm{fluoride}$ PET, and ${ }^{18}$ F-fluoride PET/CT. J. Nucl. Med. 2006, 47, 287-297. [PubMed]

26. Withofs, N.; Grayet, B.; Tancredi, T.; Rorive, A.; Mella, C.; Giacomelli, F.; Mievis, F.; Aerts, J.J.; Waltregny, D.; Jerusalem, G.; et al. ${ }^{18}$ F-fluoride PET/CT for assessing bone involvement in prostate and breast cancers. Nucl. Med. Commun. 2011, 32, 168-176. [CrossRef] [PubMed]

27. Kairemo, K.; Macapinlac, H.A. Sodium Fluoride Imaging in Oncology. In Sodium Fluoride PET/CT in Clinical Use; Kairemo, K., Macapinlac, H., Eds.; Springer: Cham, Switzerland, 2019; pp. 19-26. ISBN 978-3-030-23576-5/978-3-030-23577-2. [CrossRef]

28. Kairemo, K.; Joensuu, T. Radium-223-Dichloride in Castration Resistant Metastatic Prostate Cancer-Preliminary Results of the Response Evaluation Using F-18-Fluoride PET/CT. Diagnostics 2015, 5, 413-427. [CrossRef]

29. Kairemo, K.; Milton, D.R.; Etchebehere, E.; Rohren, E.M.; Macapinlac, H.A. Final Outcome of ${ }^{223}$ Ra-therapy and the Role of ${ }^{18}$ F-fluoride-PET in Response Evaluation in Metastatic Castration-resistant Prostate Cancer-A Single Institution Experience. Curr. Radiopharm. 2018, 11, 147-152. [CrossRef]

30. Kairemo, K.J.A. PET/Computed Tomography for Radiation Therapy Planning of Prostate Cancer. PET Clin. 2017, 12, 257-267. [CrossRef] 